\title{
THE USE OF ANTIPLATELET REVIEW AND POST PERCUTANEOUS CORONARY INTERVENTION IN PRIVATE HOSPITAL SURABAYA
}

\author{
Ike Dhiah Rochmawati ${ }^{1 *}$, Reine Risha Risthanti ${ }^{2}$, Tiara Melinda ${ }^{1}$, Susilo Vincent Renardi ${ }^{1}$ \\ ${ }^{1}$ Department of Clinical and Community Pharmacy, Faculty of Pharmacy, University of Surabaya, \\ Surabaya, Indonesia \\ ${ }^{2}$ Department of Pharmaceutical Chemistry, Faculty of Pharmacy, University of Surabaya, Surabaya, \\ Indonesia
}

*Koresponden E-mail: ikedhiah@gmail.com

DOI: https://doi.org/10.32382/mf.v16i2.1761

\section{ABSTRACT}

Antiplatelets are medicines that stop cells in the blood (platelets) from sticking together and forming a clot, which may lead to a heart attack or stroke. Furthermore, the use of antiplatelet after percutaneous coronary intervention is one of the challenge encountered by the clinicians or hospital staff because it has to be calculated between the risk-benefit ratio. This study aims to evaluate the use of dual antiplatelet therapy in patients undergoing percutaneous coronary intervention. A retrospective study was used and data were obtained from patient records. The data obtained were analysed to know the relationship between age, gender, and type of drug combination associated with ischemic events. The patient demographics were analysed descriptively, and the comparison between age and sex group related to ischemic events was analysed using chi-square analysis. There was no statistical difference in ischemic events between age and sex group. The study reported that the most commonly used DAPT profile was the combination of Aspirin $100 \mathrm{mg}$ - Clopidogrel $75 \mathrm{mg}(38 \%)$ and Aspirin $100 \mathrm{mg}$ - Ticagrelor $90 \mathrm{mg}$ (28\%). The profile of ischemic events in patients using the aspirin-clopidogrel combination was lower than that of the aspirin-ticagrelor combination.

\section{Keywords: Antiplatelet, Percutaneous Coronary Intervention, Coronary Heart Disease}

\section{BACKGROUND}

The treatments used for patients with CHD are anti-ischemic, antithrombin / anticoagulant, antiplatelet, thrombolytic / fibrinolytic and additional drugs, such as ACEinhibitors. In addition to the conventional handling of some drugs, invasive procedure was also performed in CHD handling. Percutaneous Coronary Intervention (PCI) can be used as a premier revascularization therapy in some patients. Many experts have used this method because various studies have proven that PCI is more effective than thrombolytic drugs in relieving blocked blood flow or successful revascularization. The success rate also attained 95\%. (Yahya, Fauzi. 2010; MOH, 2006). In addition, a study involving a total of $4030(3.1 \%)$ CHD patients with total occlusion that performed PCI had a successful treatment rate of $61.3 \%$. (Hannan et al, 2016). In Indonesia, PCI has been integrated into the national health insurance system.

Patients that have undergone percutaneous coranary intervention (PCI) are advice to use dual antiplatelet therapy (aspirin and platelet adenosine diphosphate [ADP] receptor antagonists to minimize complications (Richard A. Lange, and L. David Hillis, 2013). According to the European Society of Cardiology, which focuses on Dual Anti-Platelet Therapy, estimates the number of patients in need of dual antiplatelet therapy (DAPT), which is a combination of aspirin and P2Y12 platelet receptor oral inhibitors for adenosine 5'-diphosphate (ADP) that is quite large and has increased over time in the Europe. Based on the population estimates from 2015 in a region there are 1,400,000 and $2,200,000$ patients per year that have indications for DAPT after coronary intervention. (Valgimigli $\mathrm{M}$ et al, 2017)

The use of DAPT in post PCI patients is associated with a reduced risk of atherothrombotic events, which includes stent thrombosis and myocardial infarction. (Piccolo and Windecker, 2016). Other studies have also shown that DAPT is the treatment of choice for post-PCI patients with stable coronary artery disease. Long-term use of DAPT (12 months) is beneficial for reducing serious cardiovascular events, compared with the combination of aspirin and placebo in patients that have ACS with non-ST segment elevation. (Miyazaki, Yosuke et 
al, 2017). Furthermore, current evidence shows that DAPT reduces the risk of stent thrombosis across the spectrum, from acute to chronic events. However, treatment with DAPT for 1 year after PCI has the advantage of reducing the recurrence rate of attacks, which is associated with a mortality rate of $15 \%$. However, since advanced antiplatelet therapy is associated with an increased risk of bleeding, this risk must be considered for the potential benefit. (Valgimigli M et al , 2017).

The study aims to evaluate the use of dual antiplatelet therapy in patients undergone percutaneous coronary intervention (PCI).

\section{METHODS}

The observational study design was used in patients after percutaneous coronary intervention. Patient medical records was obtained for data collection, demographic, medical, and medication history. The population consists of post-PCI patients in a public hospital in Surabaya. The sample was enrolled in order to meets inclusion and exclusion criteria. The inclusion criteria were all post PCI patients with coronary heart disease using dual antiplatelet therapy (DAPT) while the exclusion criteria were all post PCI patients that had triple antiplatelet therapy. The data obtained from the results of the study were analysed descriptively. PCI with DES (Drug eluting stent) was used in this research. The data was presented in the form of narrative descriptions, tables and diagrams. The patient's progress is measured by ischemic events, which are described as recurrent ischemia or re-hospitalization for coronary artery disease.

\section{RESULTS}

94 patients were recruited for this study, according to inclusion and exclusion criterias. The characteristics of the patients in this study can be shown in Table 1 .
Table 1. Patient Characteristics

\begin{tabular}{ccc}
\hline $\begin{array}{c}\text { Patient } \\
\text { characteristics }\end{array}$ & n & $\%$ \\
\hline $\begin{array}{c}\text { Gender } \\
-\quad \text { Male }\end{array}$ & 74 & $79 \%$ \\
$-\quad$ Female & 20 & $21 \%$ \\
\hline Age & & \\
$\bullet \quad \geq 75$ & 5 & $5.32 \%$ \\
$\bullet \quad 65-<75$ & 19 & $20.21 \%$ \\
$\bullet \quad<65$ & 70 & $74.47 \%$ \\
\hline Hypertension & 15 & $16 \%$ \\
\hline Diabetes Mellitus & 20 & $21 \%$ \\
\hline Dyslipidemia & 4 & $4.2 \%$ \\
\hline Heart Failure & 13 & $14 \%$ \\
\hline Without compelling & 45 & $48 \%$ \\
indication & & \\
\hline
\end{tabular}

The cross tabulation data is shown on Table 2.

Table 2 Relationship between Gender and Ischemic Event

\begin{tabular}{lcccc}
\multicolumn{4}{c}{ Ischemic Event } \\
\cline { 1 - 4 } Gender & Ischemic & $\begin{array}{c}\text { No } \\
\text { Ischemic }\end{array}$ & Total & $\begin{array}{c}\text { P } \\
\text { value }\end{array}$ \\
\cline { 1 - 4 } Men & 32 & 42 & 74 & \\
Woman & 8 & 12 & 20 & 0.795 \\
Total & 40 & 54 & 94 & \\
\hline
\end{tabular}

The comparatively analysis between elderly and non-elderly patients for ischemic wvents was carried out. The cross tabulation is shwon on Table 3.

Table 3: Relationship between Age and Ischemic Event

\begin{tabular}{|c|c|c|c|c|}
\hline Age & Ischemic & $\begin{array}{c}\text { No } \\
\text { Ischemic }\end{array}$ & Total & $\begin{array}{c}\mathbf{P} \\
\text { value }\end{array}$ \\
\hline$\geq 75$ & 2 & 3 & 5 & \\
\hline $65-<75$ & 9 & 10 & 19 & 8 \\
\hline$<65$ & 29 & 41 & 70 & \\
\hline Total & 40 & 54 & 94 & \\
\hline
\end{tabular}

The profile of dual antiplatelet therapy in patients is shown on Table 4. 
Table 4 Relationship between DAPT and ischemic based on the duration of antiplatelet use

\begin{tabular}{lccc}
\hline \multicolumn{1}{c}{ DAPT Combination } & Ischemic Events & No Ischemic Events & P-value \\
\hline Asa 100 - Tic 90 & 2 & 5 & \multirow{2}{*}{0,157} \\
\hline Short & 14 & 7 & \\
\hline Standar & 5 & 3 & \multirow{2}{*}{0.199} \\
\hline Asa 100 - Cpg 75 & 9 & 18 & \\
\hline Short & 4 & 4 & \\
\hline Long term & & & \\
\hline Asa 80 - Cpg 75 & 0 & 15 & \\
\hline Short & 1 & 2 & \\
\hline Standar & & & \\
\hline Asa 80 - Tic 90 & 1 & 0 & \\
\hline Short & 1 & 0 & \\
\hline Standar & & & \\
\hline Cpg 75 & 2 & 0 \\
\hline Short & 1 & \\
\hline Long term & 5 & \\
\hline
\end{tabular}

Short: 0-6 months; Standar: 7-12 months; Long term: >12 months

Asa: asetylsalicylic acid; cpg: clopidogrel; tic: ticagrelor

\section{DISCUSSION}

From the characteristics of patients above at table 1 , the number of female is less than male. It is suitable with the previous study which stated woman have an increasing cardiovascular risk in post menopause age. The risk is lower than man in the same age before menopause age. Estrogen take place in atherosclerosis process in woman, especially in metabolic factors such as lipid, inflammatory marker, and coagulation system. (Maas; Appelman, 2010). Based on that theory, the difference between male and female patients according to ischemic events was analysed. The cross tabulation data is shown on Table 2. Based on p-value in table 2, it was observed that there was no difference in ischemic events between both male and female patients. The results were conflicting with the result from previous study. Certain confusing factors such as the number of patients, compelling indications, and current drug use influences the results.

As age increases, patients are at greater risk of experiencing cardiovascular event. This has been proven based on research conducted by Tsang et al, 2003 in which patients aged 70-74 years and above are at high risk of cardiovascular events as measured by the Risk-Scoring Algorithm. One of the cardiovascular risk factors that cannot be changed is age. This age factor is often use in various calculations for cardiovascular risk events such as the Framingham Risk Score and SCORE issued by the European Society of Cardiology. Furthermore, age can also affect the reactivity of platelet in the body. This event is possible because the platelet reactivity is higher older patients. Theoretically, platelet reactivity is the tendency for hyperactivation, and can be determined when antiplatelet therapy didn't show optimal effects (Nusca et al, 2012).

The comparatively analysis between elderly and non-elderly patients for ischemic wvents was carried out. The cross tabulation is shwon on Table 3 . From the p-value at table 3 , it was concluded that there was no difference in ischemic events between elderly and non-elderly patients. Another study conducted by Verdoia et al, 2010, reported that patients aged $>70$ years were more likely to experience High Residual on Treatment Platelet Reactivity (HRPR) on the use of antiplatelet agents. This is according to research conducted by Beltrame. F, John. What is the age of the most experienced CHD between 50 and 65 years (Beltrame et al., 2012). This may be because the incidence of angina also increases with age. In addition to the fact that aging also leads to a decrease in elasticity of the arterial wall, which prevents the arteries from expanding properly, which increases blood pressure and when there is infiltration of fat and cholesterol in the arteries, it become atherosclerosis and increases cardiovascular events. (Potter and Perry, 2005). The results showed no difference in ischemic events between different age groups of patients. These results indicate a difference with the results of previous studies and many factors influence the differences in the results of this study, which includes the small number of study samples and other factors such as comorbidities, other cardiovascular risk factors, and the drugs used. 
Patients undergoing percutaneous coronary intervention, received dual antiplatelet therapy. The duration of dual anti platelet therapy are categorized into several groups, such as short duration (0-6 months), standard (7-12 months), and long term (> 12 months). Some guidelines recommend using DAPT for 12 months provided the patient has no risk of bleeding. The duration is shortened when the patient experiences bleeding. The profile of dual antiplatelet therapy in patients is shown on Table 4.

From the table 4 above, it can be seen that the combination of $100 \mathrm{mg}$ aspirin and 75 $\mathrm{mg}$ clopidogrel is most commonly used to treat double platelets. The combination of Aspirin and P2Y12 Inhibtor is recommended by the ESC Guideline for Dual Antiplatelet Therapy (DAPT). DAPT is recommended in some patients, such as Acute Coronary Syndromes (ACS) or patients with PCI (Valgimigli,2017). Low-dose Aspirin (80 mg) combined with Clopidogrel $75 \mathrm{mg}$ is the second highest number of patient in this study. Aspirin act as antiplatelet by inhibit cyclo-oxygenase 1 enzyme and thromboxane production from the low dose 30$50 \mathrm{mg}$. (Montalescot, 1991; Patrono, 1985). The range of antiplatelet doses are 75-100 $\mathrm{mg}$ for Aspirin, therefore, there was no differences between dose options.

Based on the results of statistical analysis, there was no differences in ischemic events between the different duration groups of DAPT use. This is caused by the influence of other drugs combination used by patients. The major benefit of DAPT is the reduction of stent thrombosis event. The duration of DAPT treatment is recommended within 1 year, which is related to balance between the risk of ischemic and bleeding. DAPT treatment beyond 1 year in patients undergoing PCI or after Myocardial Infarction (MI), exerts most of its benefit to reduce spontaneous MI (Montalescot, 2017). Furthermore, there was a small number of patient that continue their DAPT over 1 year. Clinicians calculated the risks between ischemic and bleeding before making a decision to continue DAPT over 1 year. Some validated risk scores were validated for decision making during antiplatelet therapy duration, such as: PRECISEDAPT score (Costa, 2017) and DAPT Score (Yeh, 2016).

The duration of the use of Dual Antiplatelet Therapy (DAPT) according to ESC Focused update on dual antiplatelet therapy in coronary artery disease developed in collaboratin EACTS in 2017 is divided into 3 types, such as short DAPT, which is 3-6 months, standard/long DAPT for 12 - 24 months, and long DAPT for 30 months. This duration affect the incidence of cardiac death, MI, or ischemic after PCI. According to PCI, the use of DAPT is therefore a standard care. In post-PCI CHD patients with a diagnosis of stable CAD, when the patient has a small bleeding risk, a combination of aspirin-clopidogrel DAPT are used for 6 months. However, when the patient has a higher risk of bleeding, the combination of DAPT that are used is aspirin-clopidogrel for 1 to 3 months. In post-PCI CHD patients diagnosed with ACS both NSTEMI and STEMI, when the patient has a small risk of bleeding the combination of DAPT that are used is aspirinticagrelor or clopidogrel aspirin for 12 months. Whereas patients with a high risk of bleeding uses a combination of DAPT aspirinclopidogrel or aspirin-ticagrelor for 6 months. (Valgimigli et al, 2017).

\section{CONCLUSIONS}

There was no difference between both sex and age group with ischemic events. The most commonly use of dual antiplatelet therapy was aspirin-clopidogrel and aspirin-ticagrelor. There was no statistically significant difference between the duration of dual antiplatelet therapy and the combination of the dual antiplatelet agents.

\section{REFERENCES}

Becker et al., 2006, Sex Differences in Platelet Reactivity and Response to Low-Dose Aspirin Therapy, JAMA. 2006; 295(12):1420-1427

Borja I et al. , 2017, ESC guidlines for the management of acute myocardial infarction in patient presenting with persistent ST-segment elevation. European Heart Journal (2018) 39, 119-177

Costa F, van Klaveren D, James S, Heg D, Raber L, Feres F, Pilgrim T, Hong MK, Kim HS, Colombo A, Steg G, Zanchin T, Palmerini T, Wallentin L, Bhatt DL, Stone GW, Windecker S, Steyerberg EW, Valgimigli $M$. Derivation and validation of the predicting bleeding complications in patients undergoing stentimplantation and subsequent dual antiplatelet therapy (PRECISE-DAPT) score: a pooled analysis of individualpatient datasets from clinical trials. Lancet 2017;389:1025-1034.

D. Capodono, et al. , 2013, Antiplatelet therapy: new pharmacological agents and 
changing paradigms, $J$ Thromb Haemost 2013 Jun:11 Suppl 1:316-29

Department of Health. 2006, Pharmaceutical Care for Coronary Heart Disease Patients: The Focus of Acute Coronary Syndrome, Jakarta: Directorate of Community Pharmacy Development and the DITJEN Clinic Pharmaceutical Development and Medical Devices

Dadjau, Yahya et al, 2016, Risks and Benefits of Dual Antiplatelet Therapy Beyond 12 Months After Coronary Stenting, Medicine (Baltimore). 2016 May;95 (22)

Eikelboom, W. John., 2012, Antithrombotic Therapy and Prevention of Thrombosis. American College of Chest Physicians Evidence-Based Clinical Practice Guidelines, $\quad 9^{\text {th }}$ Edition, Volume 141, number 2

Han, Yaling, et al, 2005 , Cilostazol improves long-term outcomes after coronary stent implantation, American Heart J. 2005 Sep;150(3):568

Hannan, et al, 2016, Patient With Chronic Total Occlusions Undergoing Percutaneous Coronary Interventions: Characteristics, Success, and Outcomes. Circ Cardiovasc Interv 2016 May;9(5)

Harter et al, 2015, Anticoagulant Drug Therapy: A Review, West J Emerg Med 2015 Jan:16(1):11-7

John F. Beltrame, Rachel Dreyer and Rosanna Tavella (March 16th 2012). Epidemiology of Coronary Artery Disease, Coronary Artery Disease Current Concepts in Epidemiology, Pathophysiology, Diagnostics and Treatment, David Gaze, IntechOpen, DOI: $10.5772 / 29030$. Available from: https://www.intechopen.com/books/cor onary-artery-disease-current-conceptsin-epidemiology-pathophysiologydiagnostics-andtreatment/epidemiology-of-coronaryartery-disease

Knuuti J, Wijns W, Saraste A, Capodanno D, Barbato E, Funck-Brentano C, et al. 2019 ESC Guidelines for the diagnosis and management of chronic coronary syndromes. European Heart Journal (2019)00, 1-71
Maas, Appelman, 2010, Gender Differences in Coronary Heart Disease. Neth Heart J 2010;18:598-603

Ministry of Health Republic of Indonesia., 2014, Infodatin: Heart Health Situation, Data and Information Center Ministry of Health Republic of Indonesia, 2, (online)

Ministry of Health, 2016, Standard Rates of Health Services in the administration of the Health Insurance Program, Health Minister Regulation No. 52

Miyazaki, Yosuke et al, 2017, Single or dual Antiplatelet therapy after PCI, Nat Rev Cardiol 207 May;14(5):294-303

Montalescot G, Drobinski G, Maclouf J, Maillet F, Salloum J, Ankri A, Kazatchkine M, Eugene L, Thomas D, Grosgogeat Y. Evaluation of thromboxane production and complement activation during myocardial ischemia in patients with angina pectoris. Circulation 1991;84:2054-2062.

Nusca, Annunziata, et al, 2013, Influence of Platelet Reactivity on Clinical Outcome of Patients with Stable Coronary Artery Disease. J Cardiovasc Transl Res.213 Jun;6(3):346-54

Patrono C, Ciabattoni G, Patrignani P, Pugliese F, Filabozzi P, Catella F, Davi G, Forni L. Clinical pharmacology of platelet cyclooxygenase inhibition. Circulation 1985;72:1177-1184.

Piccolo and Windecker, 2016, Dual Antiplatelet Therapy in Percutaneous Coronary Intervention , AHA journal

Potter, P., \& Perry, A, 2005, Textbook of Fundamentals of Nursing: Concepts, Process and Practice, $4^{\text {th }}$ ed., Vol 1, Jakarta: $E G C$

Richard A. Lange., And L. David Hillis, 2013, Coronary Revascularization in Context , N Engl J Med 2009;360:10241026

Scott, et al., 2015, Antiplatelet Drug Interaction with Proton Pump Inhibitors, NIH Public Access Author Manuscript, Volume 10, number 2.

Titin Andri Wihastuti., Sri Andarini., And Teuku Heriansyah., 2016, Basic Pathophysiology of Nursing in 
Coronary Heart Disease: Vascular Inflammation, Malang: UB Press

Tsang, Teresa S. M., et al, 2003, Prediction of Risk for First Age-Related Cardiovascular Events in an Elderly Population: The Incremental Value of Echocardiography. J Am Coll Cardiol. 2003 Oct 1 ;42(7): 1199-205

Valgimigli M et al., 2017, ESC focused update on dual antiplatelet therapy in coronary artery disease developed in collaboration with EACTS. European Heart Journal (2018) 39, 213-254

Verdoia M., et al, 2016, Advanced Age and High-Residual Platelet Reactivity in Patients Receiving Dual Antipletelet Therapy with Clopidogrel or Ticagrelor. J Thromb Haemost. 2016 Jan;14(1): 5764
Wiviott, D. Stephen et al, 2007, Prasugrel versus Clopidogrel in Patients with Acute Coronary Syndromes, $N$ Engl J Med 2007; 357: 2001-2015

WHO, 2011, Global Atlas of cardiovascular disease prevention and control.

Yeh RW, Secemsky EA, Kereiakes DJ, Normand SL, Gershlick AH, Cohen DJ, Spertus JA, Steg PG, Cutlip DE, Rinaldi MJ, Camenzind E, Wijns W, Apruzzese PK, Song Y, Massaro JM, Mauri L, DAPT Study Investigators. Development and validation of a prediction rule for benefit and harm of dual antiplatelet therapy beyond 1 year after percutaneous coronary intervention. JAMA 2016;315:17351749.

(c) $\frac{1}{\mathrm{Br}}$ (2) 